\title{
Feasibility Analysis and Simulation of Integrated Renewable Energy System for Power Generation: A Hypothetical Study of Rural Health Clinic
}

\author{
Vincent Anayochukwu Ani ${ }^{1}$ and Bahijjahtu Abubakar ${ }^{2}$ \\ ${ }^{1}$ Department of Electronic Engineering, University of Nigeria (UNN), Nsukka 410001, Nigeria \\ ${ }^{2}$ Renewable Energy Programme, Federal Ministry of Environment, Abuja 900284, Nigeria \\ Correspondence should be addressed to Vincent Anayochukwu Ani; vincent_ani@yahoo.com
}

Received 30 May 2014; Revised 10 December 2014; Accepted 11 December 2014

Academic Editor: Ahmed Al-Salaymeh

Copyright (c) 2015 V. A. Ani and B. Abubakar. This is an open access article distributed under the Creative Commons Attribution License, which permits unrestricted use, distribution, and reproduction in any medium, provided the original work is properly cited.

\begin{abstract}
This paper presents the feasibility analysis and study of integrated renewable energy (IRE) using solar photovoltaic (PV) and wind turbine (WT) system in a hypothetical study of rural health clinic in Borno State, Nigeria. Electrical power consumption and metrology data (such as solar radiation and wind speed) were used for designing and analyzing the integrated renewable energy system. The health clinic facility energy consumption is $19 \mathrm{kWh} /$ day with a $3.4 \mathrm{~kW}$ peak demand load. The metrological data was collected from National Aeronautics and Space Administration (NASA) website and used to analyze the performance of electrical generation system using HOMER program. The simulation and optimization results show that the optimal integrated renewable energy system configuration consists of $5 \mathrm{~kW}$ PV array, BWC Excel-R $7.5 \mathrm{~kW}$ DC wind turbine, 24 unit Surrette 6CS25P battery cycle charging, and a $19 \mathrm{~kW}$ AC/DC converter and that the PV power can generate electricity at 9,138 $\mathrm{kWh} /$ year while the wind turbine system can generate electricity at 7,490 kWh/year, giving the total electrical generation of the system as $16,628 \mathrm{kWh} / \mathrm{year}$. This would be suitable for deployment of $100 \%$ clean energy for uninterruptable power performance in the health clinic. The economics analysis result found that the integrated renewable system has total NPC of 137,139 US Dollar. The results of this research show that, with a low energy health facility, it is possible to meet the entire annual energy demand of a health clinic solely through a stand-alone integrated renewable PV/wind energy supply.
\end{abstract}

\section{Introduction}

The global environmental concerns over the use of fossil fuels for electric power generation have increased the interest in the utilization of renewable energy resources. In particular, rapid advances in wind turbine generator and photovoltaic technologies have brought opportunities for the utilization of wind and solar resources for electric power generation worldwide [1]. Solar and wind energy systems are omnipresent, freely available, and environmental friendly, and they are considered as promising power generating sources due to their availability and topological advantages for local power generations $[2,3]$. However, a drawback, common to solar and wind options, is their unpredictable nature and dependence on weather and climatic changes, and the variations of solar and wind energy may not match with the time distribution of load demand. This shortcoming not only affects the system's energy performance, but also results in batteries being discarded too early. Generally, the independent use of both energy resources may result in considerable oversizing, which in turn makes the design costly. It is prudent that neither a stand-alone solar energy system nor a wind energy system can provide a continuous power supply due to seasonal and periodical variations $[2,4]$ for stand-alone systems. Fortunately, the problems caused by the variable nature of these resources can be partially or 
wholly overcome by integrating these two energy resources in a proper combination, using the strengths of one source to overcome the weakness of the other. The use of different energy sources allows improving the system efficiency and reliability of the energy supply and reduces the energy storage requirements compared to systems comprising only one single renewable energy source. With the complementary characteristics between solar energy and wind energy for certain locations, the integrated renewable solar/wind power generation systems with storage banks offer a highly reliable source of power [5,6], which is suitable to electrical loads that need higher reliability such as the health clinic.

Moreover, the economic aspects of these technologies are now sufficiently promising to also justify their use in smallscale stand-alone applications for residential/ranch, communication, and health clinic use; several design scenarios have been proposed for the design of solar/wind power systems for stand-alone applications [7-9].

Integrated renewable (solar/wind) energy systems use two renewable energy sources, allow improving the system efficiency and power reliability, and reduce the energy storage requirements for stand-alone applications. The integrated renewable (solar/wind) systems is becoming popular in remote area power generation applications due to advancements in renewable energy technologies.

This study is on the feasibility analysis of a health facility load data and the renewable resources and evaluates the performance of the designed stand-alone $\mathrm{PV} /$ wind generation systems.

\section{Hypothetical Study of a Rural Health Clinic in Nigeria}

A standard health clinic in rural Nigeria requiring $19 \mathrm{kWh}$ per day to run is considered and was used in the establishment of a hypothetical study for the electrical load data described by [10]. The power consumption rating that was used for the electrical load data and pattern of use are shown in Tables 1 and 2, respectively. Figure 1 shows the daily profile electricity consumption of this health clinic.

2.1. Load Variation. As from $06.00 \mathrm{hrs}$ to $08.59 \mathrm{hrs}$, load is at the least $(462 \mathrm{~W})$. The load increased a little at $09.00 \mathrm{hrs}$ $(992 \mathrm{~W})$ and at $10.00 \mathrm{hrs}$ reached a certain level $(1255 \mathrm{~W})$ and remains there till 11:59 hr and at 12:00 hr increased again and reached the highest load (3366 W). It comes down at $13.00 \mathrm{hrs}$ $(1837 \mathrm{~W})$ and remains there till $14.59 \mathrm{hrs}$, decreases little at $15.00 \mathrm{hrs}(482 \mathrm{~W})$, and remains there till $17.59 \mathrm{hrs}$ where it starts to increase again. As from 10:00 hr to 15:59 hr, most of the energy generated by solar at these times is stored in the battery for use at night with wind energy.

At night between $18.00 \mathrm{hrs}$ and $05.59 \mathrm{hrs}$, the load is minimal $(502 \mathrm{~W})$. Since wind blows much at night than in day, wind energy and the stored energy in the battery can compensate at these hours of time till day time when solar takes up.

2.2. Meteorological Data Generation for Feasibility Study. Climatic conditions determine the availability and magnitude
TABLE 1: Power consumption rating.

\begin{tabular}{lccc}
\hline Power consumption & $\begin{array}{c}\text { Power } \\
\text { (Watts) }\end{array}$ & Qty & $\begin{array}{c}\text { Load } \\
\text { (watt } \times \text { qt) }\end{array}$ \\
\hline Vaccine refrigerator/freezer & 60 & 1 & 60 \\
Small refrigerator (nonmedical use) & 300 & 1 & 300 \\
Centrifuge & 575 & 1 & 575 \\
Hematology mixer & 28 & 1 & 28 \\
Microscope & 15 & 1 & 15 \\
Security light & 10 & 4 & 40 \\
Lighting & 10 & 2 & 20 \\
Sterilizer oven (laboratory & 1,564 & 1 & 1,564 \\
autoclave) & 400 & 1 & 400 \\
Incubator & 1,000 & 1 & 1,000 \\
Water bath & & 1 & \\
Communication via VHF radio & 2 & & 2 \\
Stand-by & 30 & & 30 \\
Transmitting & 200 & 2 & 400 \\
Desktop computer & 65 & 1 & 65 \\
Printer & &
\end{tabular}

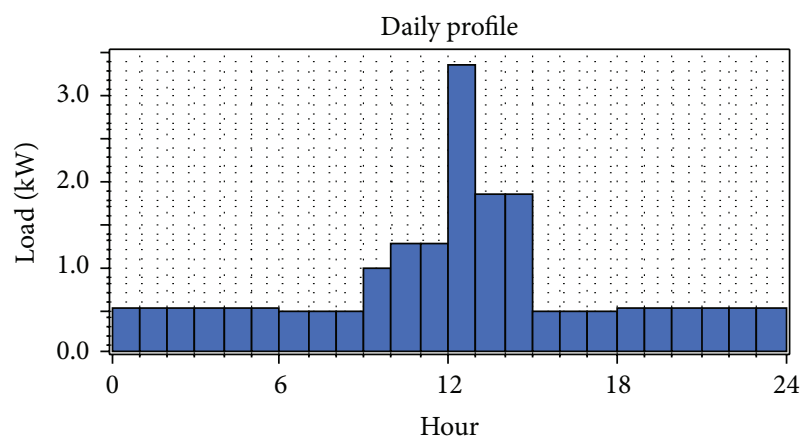

FIGURE 1: Daily load profile of the health clinic (load variation).

of solar and wind energy at a particular location. For different districts and locations, climatic conditions, including solar radiation, wind speed, and air temperature, are always changing. At the potential location, an analysis of the characteristics of solar radiation and wind conditions were made for better utilization of the solar and wind energy resources.

The data for monthly average solar radiation and wind speed for a given year (2013) were obtained from National Aeronautics and Space Administration (NASA) [11]. The specific geographical location (latitude and longitude) of the health clinic in Guzamala (Borno State) is at a location of $11^{\circ} 05^{\prime} \mathrm{N}$ latitude and $13^{\circ} 00^{\prime} \mathrm{E}$ longitude. This location has an annual average solar radiation of $5.90 \mathrm{kWh} / \mathrm{m}^{2} / \mathrm{d}$, whereas its annual average wind is $3.8 \mathrm{~m} / \mathrm{s}$. In the solar resource, March was the sunniest month of the year. In this month (March), the solar energy resource is $6.7 \mathrm{kWh} / \mathrm{m}^{2} /$ day, while in August it is only $5.1 \mathrm{kWh} / \mathrm{m}^{2} /$ day, whereas, in the wind resource, September is the least windy month of the year while April 
TABLE 2: The electrical load (daily load demands) data for a health facility.

\begin{tabular}{|c|c|c|c|c|c|c|c|c|c|c|c|c|c|c|c|}
\hline \multirow{2}{*}{ Time } & \multicolumn{14}{|c|}{ Daily load demands } & \multirow{2}{*}{ Total/hr } \\
\hline & 1 & 2 & 3 & 4 & 5 & 6 & 7 & 8 & 9 & 10 & 11 & 12 & 13 & 14 & \\
\hline $0.00-0.59$ & 60 & & & & & 40 & & & 400 & & 2 & & & & 502 \\
\hline $1.00-1.59$ & 60 & & & & & 40 & & & 400 & & 2 & & & & 502 \\
\hline $2.00-2.59$ & 60 & & & & & 40 & & & 400 & & 2 & & & & 502 \\
\hline $3.00-3.59$ & 60 & & & & & 40 & & & 400 & & 2 & & & & 502 \\
\hline $4.00-4.59$ & 60 & & & & & 40 & & & 400 & & 2 & & & & 502 \\
\hline $5.00-5.59$ & 60 & & & & & 40 & & & 400 & & 2 & & & & 502 \\
\hline $6.00-6.59$ & 60 & & & & & & & & 400 & & 2 & & & & 462 \\
\hline $7.00-7.59$ & 60 & & & & & & & & 400 & & 2 & & & & 462 \\
\hline $8.00-8.59$ & 60 & & & & & & & & 400 & & 2 & & & & 462 \\
\hline $9.00-9.59$ & 60 & & & & 15 & & 20 & & 400 & & 2 & 30 & 400 & 65 & 992 \\
\hline $10.00-10.59$ & 60 & 300 & & 28 & 15 & & 20 & & 400 & & 2 & 30 & 400 & & 1255 \\
\hline $11.00-11.59$ & 60 & 300 & & 28 & 15 & & 20 & & 400 & & 2 & 30 & 400 & & 1255 \\
\hline $12.00-12.59$ & 60 & 300 & 575 & & 15 & & 20 & 1564 & 400 & & 2 & 30 & 400 & & 3366 \\
\hline $13.00-13.59$ & 60 & 300 & 575 & & 15 & & 20 & & 400 & & 2 & & 400 & 65 & 1837 \\
\hline $14.00-14.59$ & 60 & 300 & & & & & 20 & & 400 & 1000 & 2 & & & 65 & 1847 \\
\hline $15.00-15.59$ & 60 & & & & & & 20 & & 400 & & 2 & & & & 482 \\
\hline $16.00-16.59$ & 60 & & & & & & & & 400 & & 2 & & & & 462 \\
\hline $17.00-17.59$ & 60 & & & & & & & & 400 & & 2 & & & & 462 \\
\hline $18.00-18.59$ & 60 & & & & & 40 & & & 400 & & 2 & & & & 502 \\
\hline $19.00-19.59$ & 60 & & & & & 40 & & & 400 & & 2 & & & & 502 \\
\hline $20.00-20.59$ & 60 & & & & & 40 & & & 400 & & 2 & & & & 502 \\
\hline $21.00-21.59$ & 60 & & & & & 40 & & & 400 & & 2 & & & & 502 \\
\hline $22.00-22.59$ & 60 & & & & & 40 & & & 400 & & 2 & & & & 502 \\
\hline $23.00-23.59$ & 60 & & & & & 40 & & & 400 & & 2 & & & & 502 \\
\hline Total & 1440 & 1500 & 1150 & 56 & 75 & 480 & 140 & 1564 & 9600 & 1000 & 48 & 120 & 2000 & 195 & 19368 \\
\hline
\end{tabular}

1: Vaccine refrigerator/freezer, 2: Small refrigerator (nonmedical use), 3: Centrifuge, 4: Hematology mixer, 5: Microscope, 6: Security light, 7: Lighting, 8: Sterilizer oven (laboratory autoclave), 9: Incubator, 10: Water bath, 11: Communication via VHF radio stand-by, 12: Communication via VHF radio transmitting, 13: Desktop computer, 14: Printer.

and March are the windiest. Figures 2(a) and 2(b) show the solar and wind resource profile of this location.

2.3. Solar Radiation Variation. In the months of September, October, January, February, and March, the solar radiation increases with differences from month to month as (0.43), (0.32), (0.26), (0.69), and (0.40), respectively, whereas, in the months of April, May, June, July, August, November, and December, the solar radiation decreases with differences from month to month as (0.08), (0.26), (0.39), (0.54), (0.29), (0.05), and (0.49), respectively.

2.4. Wind Speed Variation. In the months of January and February, the wind speed remains the same without differences from the months. In the months of March, April, October, November, and December, the wind speed increases with differences from month to month as (0.4), (0.1), (0.3), (0.6), and (0.5), respectively. In the months of May, June, July, August, and September, the wind speed decreases with differences from month to month as $(0.4),(0.7),(0.2),(0.2)$, and (0.2), respectively. In the months of July, August, and September the wind speed has constant decrease of (0.2) differences from month to month.

The difference in months falls in the range of 0.1-0.7, and these differences are due to earth's rotation.

2.5. System Configuration. The block diagram for a typical stand-alone PV/wind generating system is shown in Figure 3. The system consists of PV panels, wind turbine generator, storage batteries, and dump load. These technologies generate DC current-PV, wind, and battery - and are connected to the $\mathrm{DC}$ bus $\left(V_{\mathrm{DC}}\right)$. An inverter, or a DC-to-AC converter, is used to convert DC current $\left(I_{\text {inv_DC }}\right)$ to AC current $\left(I_{\text {inv_AC }}\right)$. The generating system (PV/Wind) supplied to the load and the storage batteries are charged when the renewable energy (wind and solar) generation exceeds the load demand until a specified upper limit for the battery voltage is reached, when it can no longer accept current. At this point the excess available power is diverted to the dump load (a device that sheds excess energy produced by the system), which 


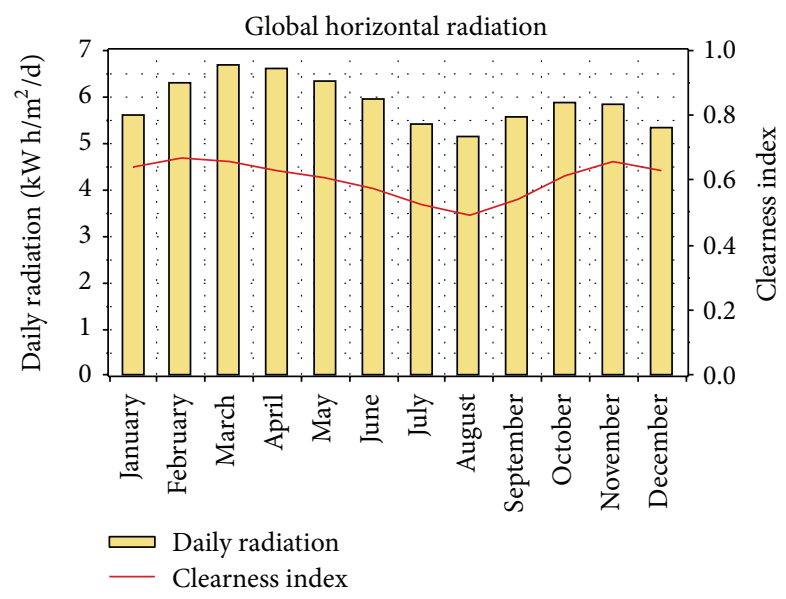

(a)

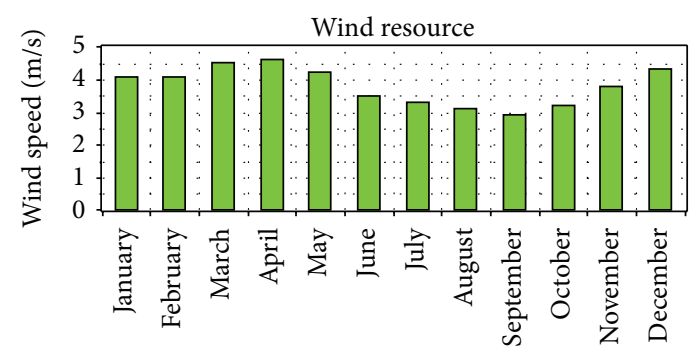

(b)

FIGURE 2: (a) HOMER output graphic for solar (clearness index and daily radiation) profile. (b) HOMER output graphic for wind speed profile.

in this study is assumed to be an electric water heater, and the remaining power sold to the community. Batteries will discharge, supplying power to the load when demand exceeds generation. They will continue discharging until a specified lower limit for the battery voltage is reached. At that point, the batteries will stop supplying power to the load, and the renewable energy if available will supply the required power to the load.

\section{Modeling and Simulation of Integrated Renewable Solar/Wind System Components}

The HOMER software was used to design an optimal integrated renewable power system. The description of HOMER can be found in Ani [12]. Reference to relevant literature provided the design guidelines. The capital costs of all the system components used for the study were gotten from PV system suppliers in Nigeria [13]. The price of PV system is $\$ 2000 / \mathrm{kW}$, while a wind turbine (BWC Excel-R) system costs $\$ 27,000$ and a Surrette 6CS25P battery costs $\$ 1,145$. The project lifetime is estimated at 20 years and the yearly interest rate applied is $6 \%$. A schematic diagram of an integrated renewable energy system is shown in Figure 4.

\section{Results}

\subsection{Cost of System Component Summary}

4.1.1. Solar PV Panels. The proposed PV module is rated at $5 \mathrm{~kW}$. The initial cost of the modules is $\$ 10,000$, and its operation and maintenance cost is $\$ 57$, with the total NPC (for the PV module only) of $\$ 10,057$, as can be seen in Figure 5. The lifetime of the modules will last the project.

4.1.2. Wind Turbine. The BWC Excel-R wind turbine has a capacity of $7.5 \mathrm{~kW}$. Its initial cost is $\$ 27,000$, and its operation and maintenance cost is $\$ 3,441$, with the total NPC (for the wind turbine only) of $\$ 30,441$. The turbine is estimated to last the project.

4.1.3. Battery. The Surrette $6 \mathrm{CS} 25 \mathrm{P}$ battery is rated at $6 \mathrm{~V}$ and has a capacity 1,156 Ah. Twenty-four batteries initially cost $\$ 27,480$ and the replacement cost and the operation and maintenance cost add a further $\$ 11,927$ and $\$ 55,056$, respectively, and a salvage cost of $\$-2,494$ having the total NPC (for the batteries only) of $\$ 91,968$.

4.2. Converter. The converter is rated $19 \mathrm{~kW}$. Its initial cost is $\$ 3,800$, and its operation and maintenance cost is $\$ 872$, with the total NPC (for the converter only) of $\$ 4,672$. The converter is estimated to last the project.

4.3. Integrated Renewable Energy System Component. The integrated renewable energy component system has total capital of $\$ 68,280$; the replacement cost and the operation and maintenance cost add a further $\$ 11,927$ and $\$ 59,426$, respectively, and a salvage cost of $\$-2,494$, giving the total NPC (for the coupled (complete) system) of $\$ 137,139$, as shown in the appendix (Figure 9). This can convince policy makers of the worthiness of the investment in integrated or single renewable energy.

4.4. Electricity Production. The average solar radiation in this location is relatively high. This gives a relatively good possibility and opportunity to engage the photovoltaic (PV) technique and technology as a component of an integrated renewable PV/wind energy system in order to produce clean energy for powering health clinic loads. Although wind speed is relatively moderate with an average of $3.8 \mathrm{~m} / \mathrm{s}$ throughout the year, it compensates for solar during the months of poor radiation.

It can be noticed that more solar irradiance can be expected from the month of February to June while less solar irradiance is to be expected from December to January. On the other hand, more wind speed can be expected from the month of December to May while less wind speed is to be expected from August to October.

Solar PV compliment wind power during the months (August, September, and October) of poor wind speed, while wind compensates for solar power during the months (December and January) when solar radiation is less as shown in Figure 6. 


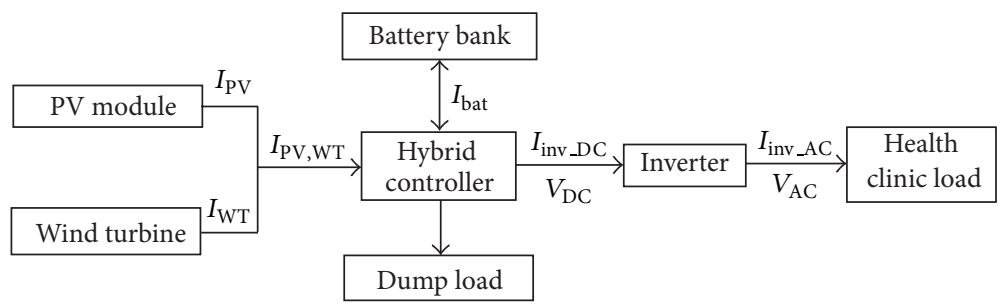

Figure 3: Configuration of the integrated renewable (PV/wind) energy system with the energy storage and dump load.

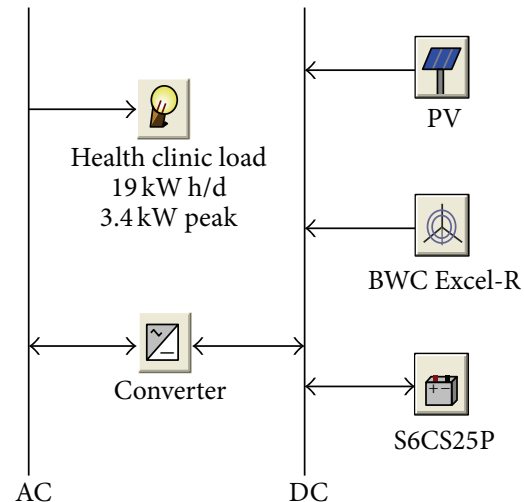

FIGURE 4: The network architecture for the HOMER simulator (proposed PV/wind power system).

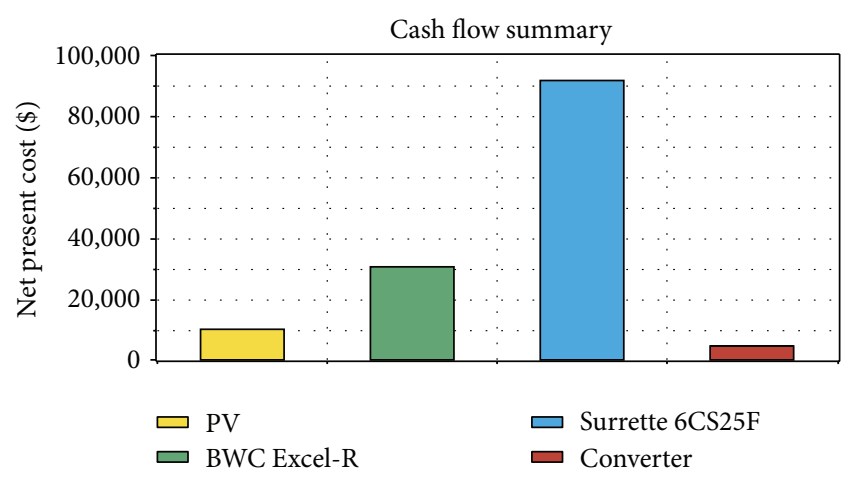

Figure 5: Net present cost of components of the integrated renewable PV/wind energy system.

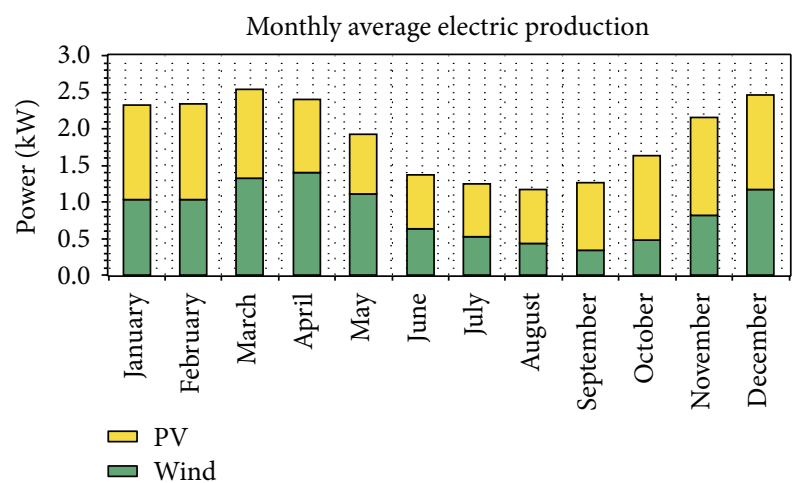

FIGURE 6: Electrical production of integrated renewable PV/wind energy system.

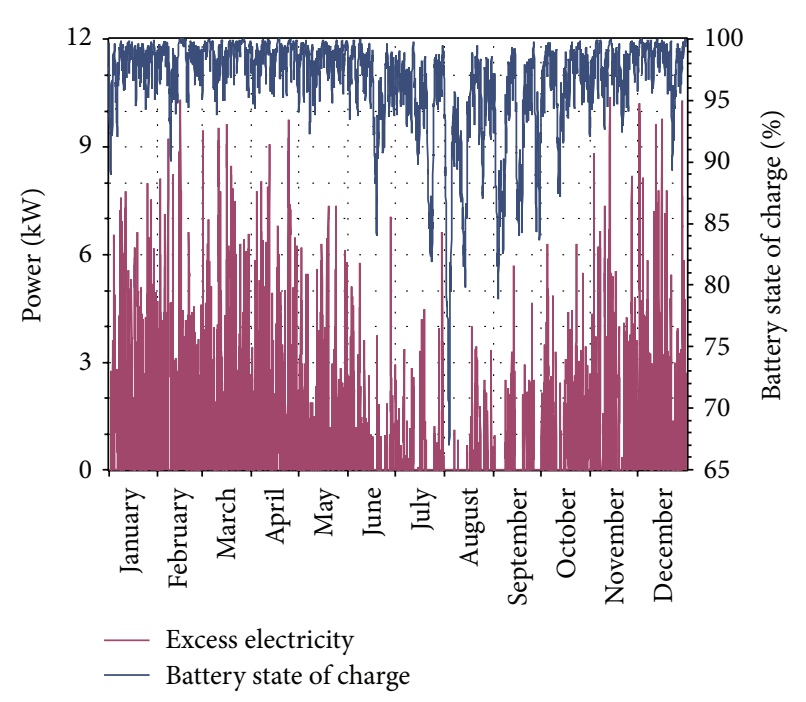

FIgURE 7: Excess electricity versus battery state of charge.

TABLE 3: Simulation results of the electricity production (kWh/yr), battery and inverter losses, and excess energy of the energy system configuration (PV/wind).

\begin{tabular}{lcc}
\hline System operation & \multicolumn{2}{c}{ PV/wind system } \\
\hline Consumption & $\mathrm{kWh} / \mathrm{yr}$ & $\%$ \\
DC primary load & 7,082 & 100 \\
The total load to be supplied & $\mathbf{7 , 0 8 2}$ & $\mathbf{1 0 0}$ \\
\hline Production & $\mathrm{kWh} / \mathrm{yr}$ & $\%$ \\
PV array & 9,138 & 55 \\
Wind turbine & 7,490 & 45 \\
Total energy generated & $\mathbf{1 6 , 6 2 8}$ & $\mathbf{1 0 0}$ \\
\hline Losses & \multicolumn{2}{c}{$\mathrm{kWh} / \mathrm{yr}$} \\
Battery & \multicolumn{2}{c}{460} \\
Inverter & \multicolumn{2}{c}{1,250} \\
Total losses & \multicolumn{2}{c}{$\mathbf{1 , 7 1 0}$} \\
Excess energy going to dump load & \multicolumn{2}{c}{7,836} \\
Total energy supplied to the load & \multicolumn{2}{c}{7,082} \\
\hline
\end{tabular}

The integrated renewable energy system (PV/Wind) produces $9,138 \mathrm{kWh} / \mathrm{yr}(55 \%)$ from solar PV array and $7,490 \mathrm{kWh} / \mathrm{yr}(45 \%)$ from wind turbine making a total of $16,628 \mathrm{kWh} / \mathrm{yr}(100 \%)$ as shown in Table 3 and Figure 10 in the appendix. The load demand is $7,082 \mathrm{kWh} / \mathrm{yr}$, while the 


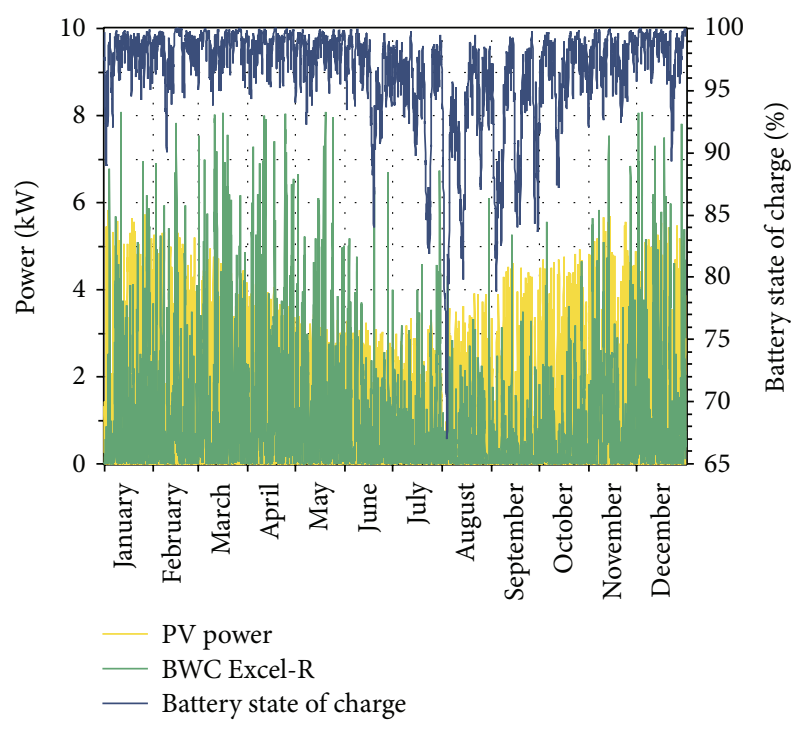

FIGURE 8: Integrated renewable energy (PV/Wind) versus battery state of charge.

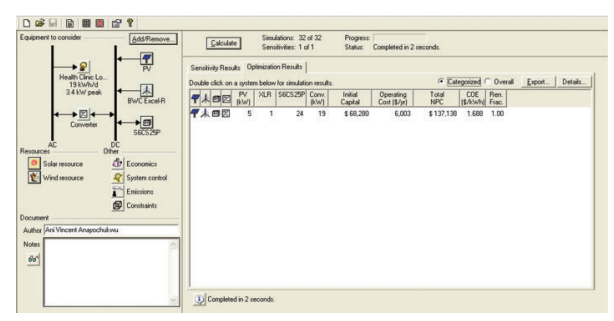

FIGURE 9: The network architecture for the HOMER simulator, proposed $\mathrm{PV} /$ wind power system and its optimization results.

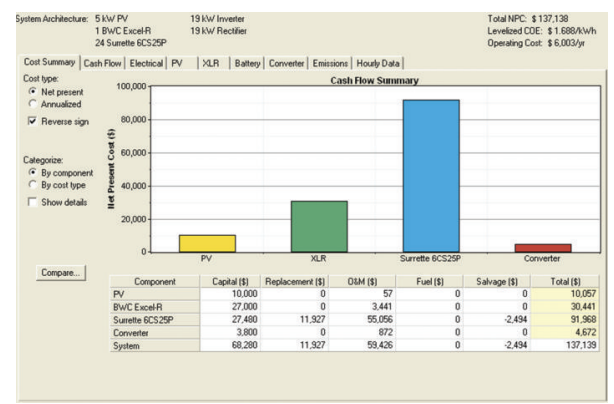

FIgURE 10: Cost summary of the integrated renewable energy system.

excess electricity from the system is $7,836 \mathrm{kWh} / \mathrm{yr}$ also shown in Table 3 and Figure 10 in the appendix.

4.5. Excess Electricity. Excess electricity always occurs when the battery state of charge (SOC) is at $93 \%$ upwards and discharges less (at the rate of $1.5 \mathrm{~kW}$ to $2.5 \mathrm{~kW}$ ) and this is between Novembers and Mays. Between Junes and Octobers when the integrated renewable (solar radiation and wind speed) is low, the battery SOC is at $92 \%$ downward and

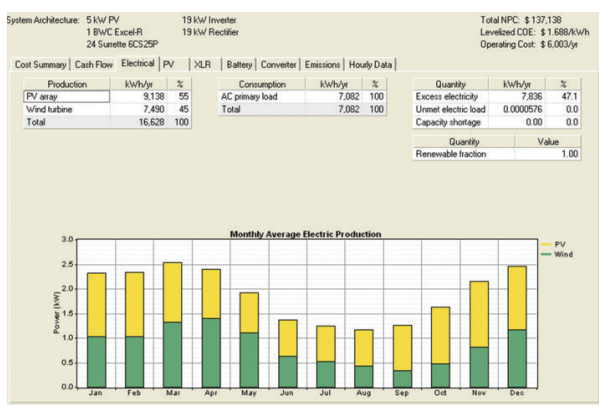

FIGURE 11: Electricity production summary of the integrated renewable energy system.

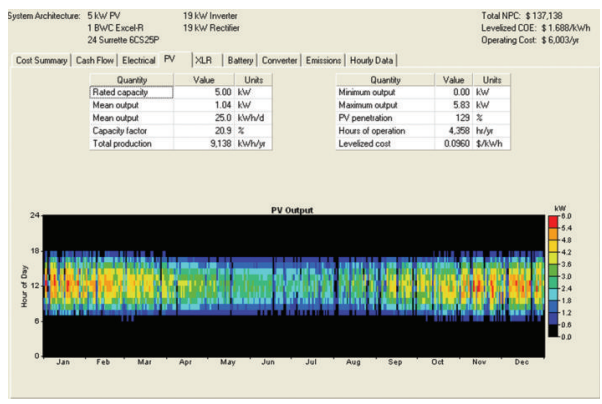

FIGURE 12: PV output summary.

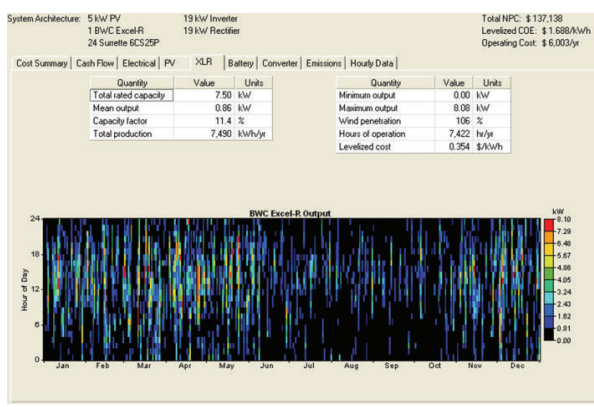

FIGURE 13: Wind turbine (BWC Excel-R) output summary.

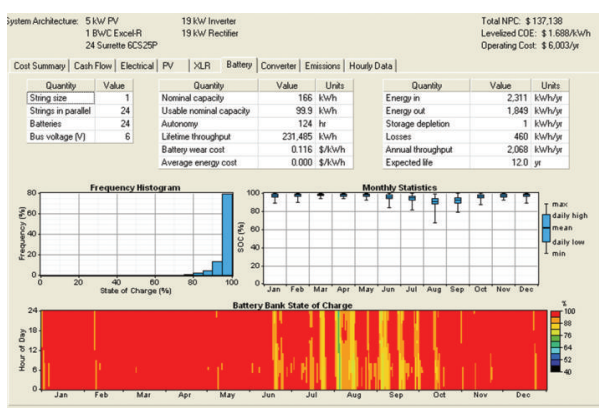

FIGURE 14: Battery bank state of charge summary.

discharges much (at the rate of $3 \mathrm{~kW}$ to $10 \mathrm{~kW}$ ) and there will be no excess electricity from this point downward (due to poor solar radiation and less wind speed) as shown in Figures 7 and 8. 


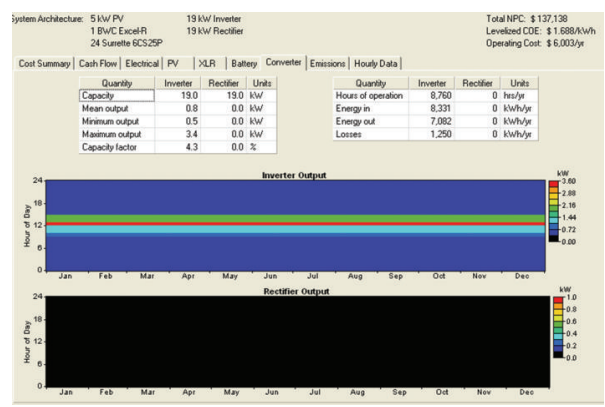

FIGURE 15: Converter output summary.

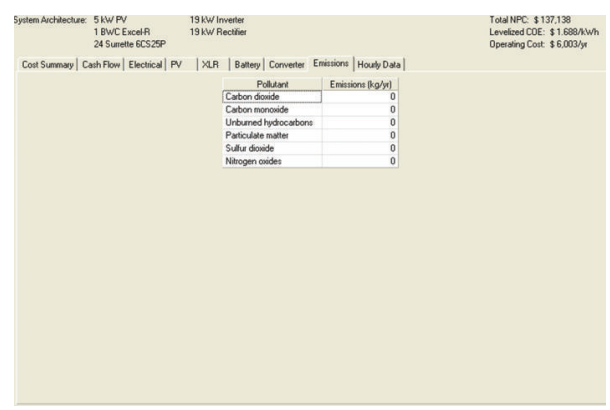

FIGURE 16: Emission output summary.

\section{Conclusion}

This paper describes the feasibility study of load data and the renewable resources and evaluates the performance of the designed stand-alone PV/wind generation systems. Hourly average wind speed and solar radiation data from the site for the generating unit and the anticipated load data are used to predict the general performance of the generating system. These power systems are very well suited to supply the specific load demand of the rural health clinic that presents a peak in the day time (afternoon) when the solar radiation is maximum and minimal load at night time when the wind blows much (since wind blows much at night than in day). Such performance evaluations are useful in estimating the component sizes needed for generation systems to supply power to loads reliably. It is also helpful in performing a detailed economic analysis (cost benefit study) for the generating unit. Of particular interest is the introduction of dump load model. The excess wind and solargenerated power, when available, are used to heat water in an electric water heater, and the remaining power is sold to the community. This heated water can be used for any purposes in the health clinic such as drinking water. Finally, in the integrated renewable $\mathrm{PV} /$ wind energy system, there is no fuel consumption, which means no emission of $\mathrm{CO}_{2}, \mathrm{CO}, \mathrm{UHC}$, $\mathrm{PM}, \mathrm{SO}_{2}$, and $\mathrm{NO}_{x}$ from the energy system. This system configuration would be suitable for deployment of $100 \%$ clean energy for uninterruptable power performance.

\section{Conflict of Interests}

The authors declare that there is no conflict of interests regarding the publication of this paper.

\section{References}

[1] M. H. Nehrir, B. J. LaMeres, G. Venkataramanan, V. Gerez, and L. A. Alvarado, "An approach to evaluate the general performance of stand-alone wind/photovoltaic generating systems," IEEE Transactions on Energy Conversion, vol. 15, no. 4, pp. 433439, 2000.

[2] V. A. Ani, "Optimal energy system for single household in Nigeria," International Journal of Energy Optimization and Engineering, vol. 2, no. 3, pp. 16-41, 2013.

[3] W. Zhou, C. Lou, Z. Li, L. Lu, and H. Yang, "Current status of research on optimum sizing of stand-alone hybrid solar-wind power generation systems," Applied Energy, vol. 87, no. 2, pp. 380-389, 2010.

[4] H. Yang, W. Zhou, L. Lu, and Z. Fang, "Optimal sizing method for stand-alone hybrid solar-wind system with LPSP technology by using genetic algorithm," Solar Energy, vol. 82, no. 4, pp. 354$367,2008$.

[5] H. Yang, L. Lu, and W. Zhou, "A novel optimization sizing model for hybrid solar-wind power generation system," Solar Energy, vol. 81, no. 1, pp. 76-84, 2007.

[6] F. Giraud and Z. M. Salameh, "Steady-state performance of a grid-connected rooftop hybrid wind-photovoltaic power system with battery storage," IEEE Transactions on Energy Conversion, vol. 16, no. 1, pp. 1-7, 2001.

[7] W. D. Kellogg, M. H. Nehrir, G. Venkataramanan, and V. Gerez, "Generation unit sizing and cost analysis for stand-alone wind, photovoltaic, and hybrid wind/PV systems," IEEE Transactions on Energy Conversion, vol. 13, no. 1, pp. 70-75, 1998.

[8] R. Chedid and S. Rahman, "Unit sizing and control of hybrid wind-solar power systems," IEEE Transactions on Energy Conversion, vol. 12, no. 1, pp. 79-85, 1997.

[9] R. Yokoyama, K. Ito, and Y. Yuasa, "Multiobjective optimal unit sizing of hybrid power generation systems utilizing photovoltaic and wind energy," Journal of Solar Energy Engineering, vol. 116, no. 4, pp. 167-173, 1994.

[10] V. A. Ani and A. N. Emetu, "Simulation and optimization of photovoltaic/diesel hybrid power generation system for health service facilities in rural environments," Electronic Journal of Energy and Environment, vol. 1, no. 1, 2013.

[11] NASA, 2013, http://eosweb.larc.nasa.gov/.

[12] V. A. Ani, "Feasibility assessment of a PV-diesel hybrid power system for an isolated off-grid catholic church," Electronic Journal of Energy and Environment, vol. 3, no. 1, 2013.

[13] Renewable Energy Shop in Nigeria, http://www.solarshopnigeria.com/.

\section{Appendix}

See Figures 9, 10, 11, 12, 13, 14, 15, and 16 . 


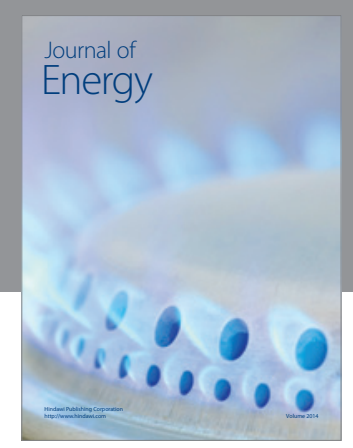

Journal of

Industrial Engineering
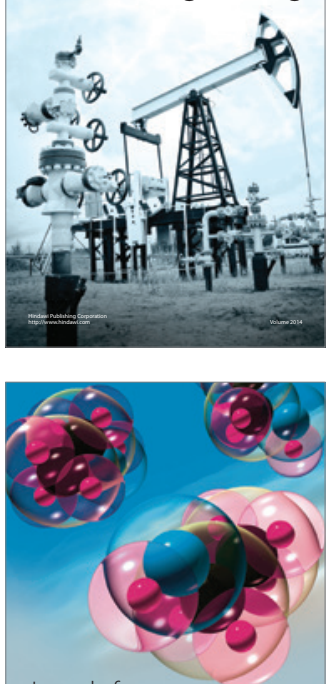

Fuels
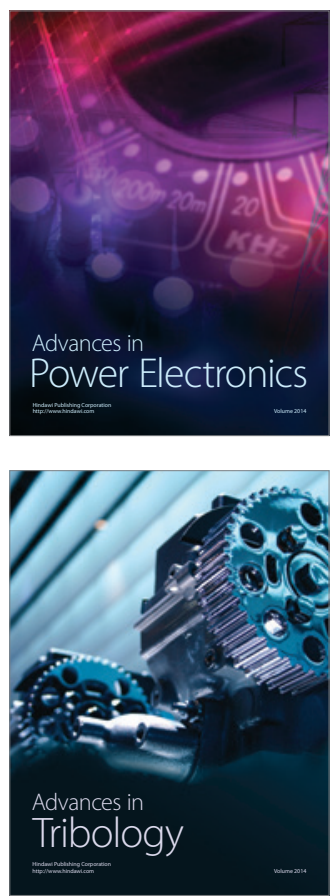

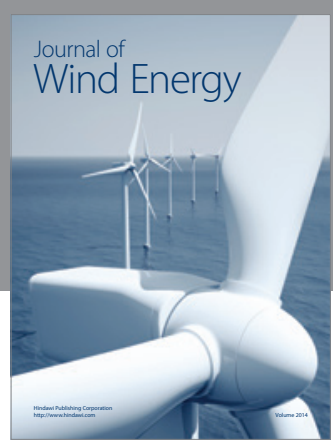

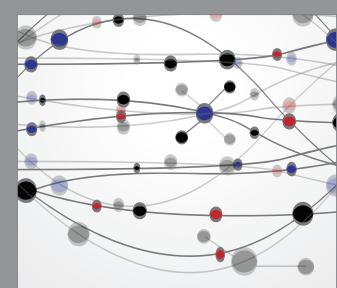

The Scientific World Journal

Submit your manuscripts at http://www.hindawi.com

Journal of

Structures
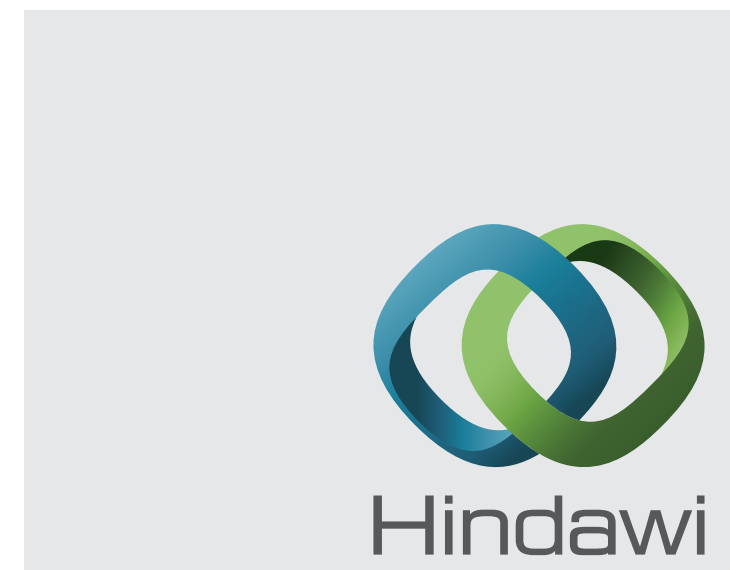

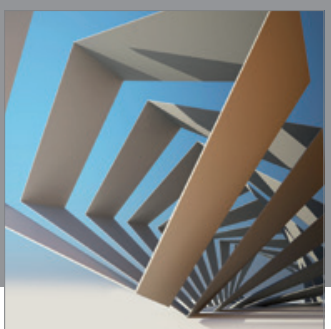

Rotating

Machinery
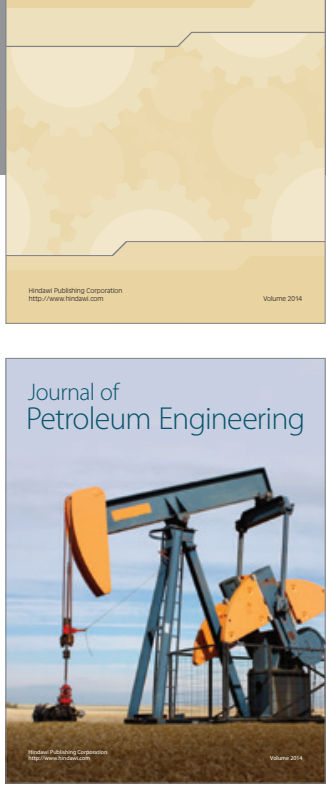

Journal of

Solar Energy
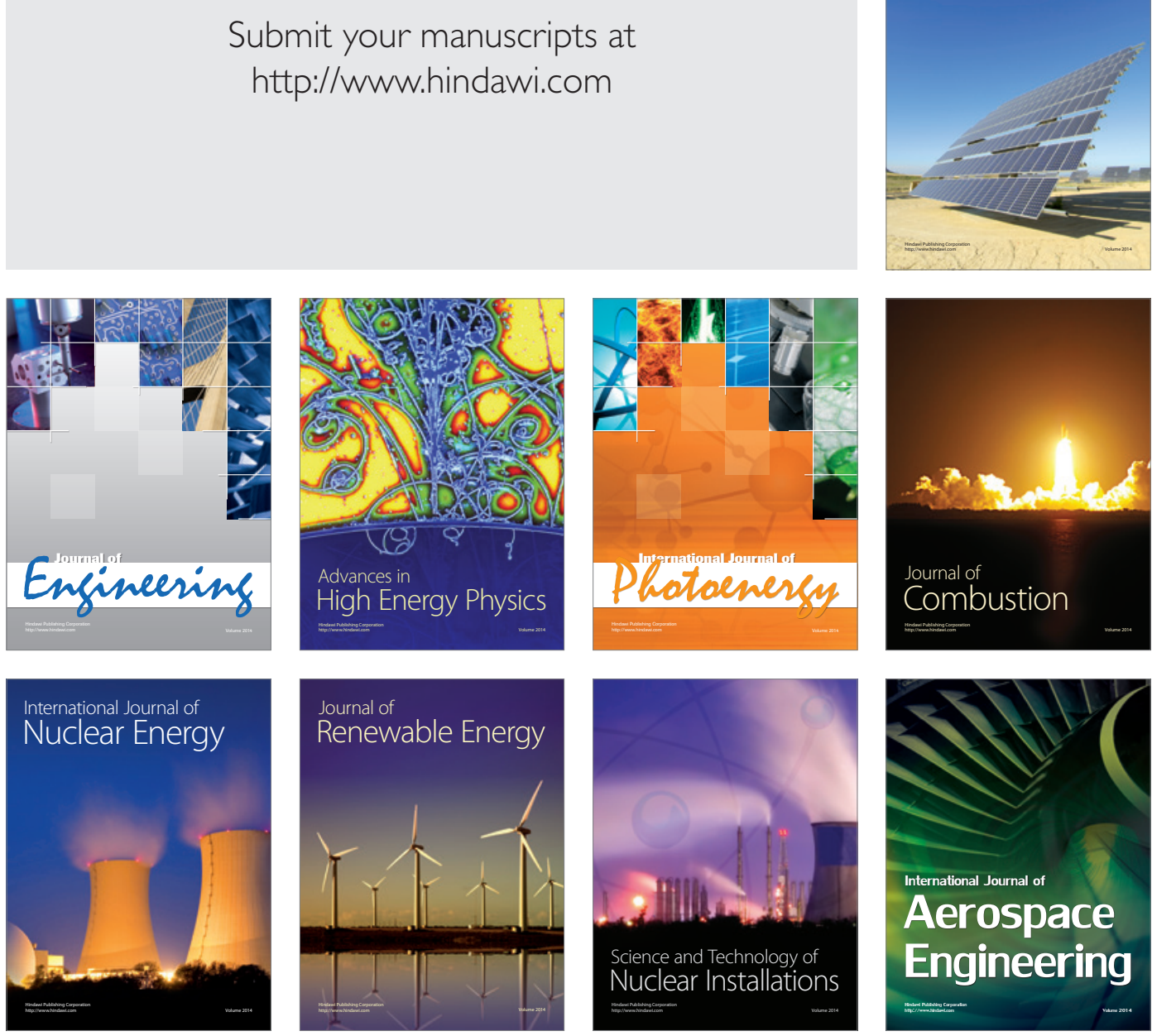